\title{
Requirements, in terms of root canal treatment, of undergraduates in the European Union: an audit of teaching practice
}

IN BRIEF

- Provides recent information on the output of EU dental students in the area of root canal treatment.

- Questions the use of 'competence' in assessment of an undergraduate

- Provides an insight into the possible amount of experience new graduates are likely to have had in RCT - useful for those involved in VT training schemes or similar.

\author{
S. Gatley, ${ }^{1}$ J. Hayes ${ }^{2}$ and C. Davies ${ }^{3}$
}

\section{VERIFIABLE CPD PAPER}

Aim The purpose of this study was to gather information from across the EU about requirements of dental undergraduates in the area of root canal treatment (RCT). Methodology One hundred and ninety-two EU dental schools were invited to complete an online survey. The survey inquired about assessment in RCT, whether students complete a minimum number of RCTs, whether this includes both anterior and posterior teeth, and if root canal retreatment and endodontic surgery are compulsory. The final question asked how competence in RCT can be described. Results Forty-eight dental schools in 20 countries responded. Results showed variation in assessment methods. Ninety-four percent insist on students performing $\mathrm{RCT}$ in anterior and posterior teeth. Eighty-one percent ensure students perform a minimum number and there is considerable variation in what that minimum number is. Seventy-nine percent require undergraduates to perform retreatment and $4 \%$ require them to perform endodontic surgery. Descriptions of what might constitute competence in RCT varied greatly. Conclusions Despite convergence of the undergraduate curriculum being endorsed by many and movement of dentists within the EU escalating, there is still inconsistency in the output of dental schools with regard to RCT. This sample demonstrated deviation from the ESE's 2001 Undergraduate Curriculum Guidelines for Endodontology.

\section{INTRODUCTION}

Untreated apical periodontitis has a high prevalence within the European population. ${ }^{1-4}$ Studies in European countries have also demonstrated that the standard of root canal treatment provided is generally not high. ${ }^{5-9}$ There is a clear need for dental practitioners who are able to address this current dental health issue.

In the year leading up to March 2006 almost $46 \%$ of new National Health Service dentists qualified outside of the United Kingdom..$^{10}$ This proportion is the highest recorded for the last ten years, and the majority of these new recruits came from within the European Union (EU). The EU openly encourages freedom of movement between member states for dental professionals, but with such an escalated influx

${ }^{1}$ Senior House Officer in Restorative Dentistry, ${ }^{2}$ Honorary Associate Specialist \& Lecturer in Restorative Dentistry, ${ }^{3}$ Information \& Development, Manager, School of Dentistry, Heath Park, Cardiff, CF14 4XY

${ }^{*}$ Correspondence to: Miss Sarah Gatley

Email: sarahlouisegatley@ hotmail.co.uk

\section{Refereed Paper}

Accepted 22 June 2009

DOI: $10.1038 /$ sj.bdj.2009.716

${ }^{\circledR}$ British Dental Journal 2009; 207: 165-170 of non-UK graduates, do we have any guarantee that schools across the EU are providing comparable degrees? It would be beneficial for all EU dental graduates to have reached a mutually-agreed level of competency in specified subjects. This would ensure appropriate protection of the public. It would also benefit the European graduate applying for employment and his/her prospective employer.

\section{Dental education in Europe}

Clearly, there are variations in disease expression, culture, politics, history, languages and traditions across the 27 countries of the EU. Considering the influence these variants have on healthcare in general, it is not surprising to find noticeable distinctions in dental education across the continent. While some diversity is, to a degree, inevitable and should be encouraged, many of those involved in dental education believe harmonisation of the EU undergraduate dental curriculum to be key to provision of a high-standard of dental care throughout Europe. ${ }^{11,12}$ Harmonisation of curricula is a lengthy and complex process, but already many efforts have been made to encourage EU dental schools to converge in this area. One manifestation of this is the ERASMUS scheme, which promotes the exchange of students and teachers within the European community. ERASMUS was developed in 1987 with a view to "enhance the quality and reinforce the European dimension of higher education' and to boost European mobility 'improving the transparency and full academic recognition of studies and qualifications throughout the Union. ${ }^{13}$

In June 1999, Ministries of Education of the EU countries signed the Bologna Declaration. This declaration pinpointed the desirability of 'the effective exercise of free movement' in the workforce, and 'adoption of a system of easily readable and comparable degrees' across the EU. ${ }^{14}$ Since 1978 EU law has contained the Dental Directives, ${ }^{15}$ which require member states to recognise qualifications awarded by other members and outline subjects to be covered in undergraduate dental training. In accordance, dental qualifications gained in the EU by nationals of EU member states, are eligible for registration with the GDC in the UK. Other EU member 
states have reciprocal arrangements for registration. The Dental Directive, 78/687/ EEC, covers course content and provides a basic framework around which a curriculum should be built. However, Shanley et al. ${ }^{16}$ demonstrated that there was little convergence of curricula within EU dental schools and suggested that the Dental Directives alone offer no guarantee of the standard of dental education.

Following Shanley's findings in 1997, the EU funded the DentEd Project. This project set out to encourage convergence towards a higher standard of dental education in member countries through peer review, communication and sharing of best practices and innovations. The DentEd Project (1997-2000) developed into DentEd Evolves (2000-2003) and the current project DentEd III (2004-2007). In 2005 DentEd III published its 'Profile and Competences Document' (PCD). ${ }^{17}$ This document was published for dental schools across Europe to use as a foundation to build their courses around.

\section{Teaching of root canal treatment in the UK}

In the UK and many European countries, root canal treatment is considered a routine part of primary dental care. This is usually reflected by its inclusion in the undergraduate curriculum, but there have been studies demonstrating a wide variation in student experience and teaching even within a single country. ${ }^{18-20}$ In the UK, it is the responsibility of the General Dental Council (GDC) to regulate the undergraduate curriculum. In 2002 the GDC published a second edition of The first five years which outlines their requirements for content and delivery of the undergraduate dental degree programme. They require graduates to be 'competent at completing endodontic treatments of single and multi-rooted teeth. ${ }^{21}$ It is also clearly stated within the Profile and Competences Document that the dental graduate must 'be competent to perform endodontic treatment on uncomplicated single and multi-rooted teeth' and 'be competent to recognize indications for surgical and complicated non-surgical root canal therapy and take appropriate action. ${ }^{17}$ In 2001, the European Society of Endodontology issued its 'Undergraduate Curriculum Guidelines for Endodontology'

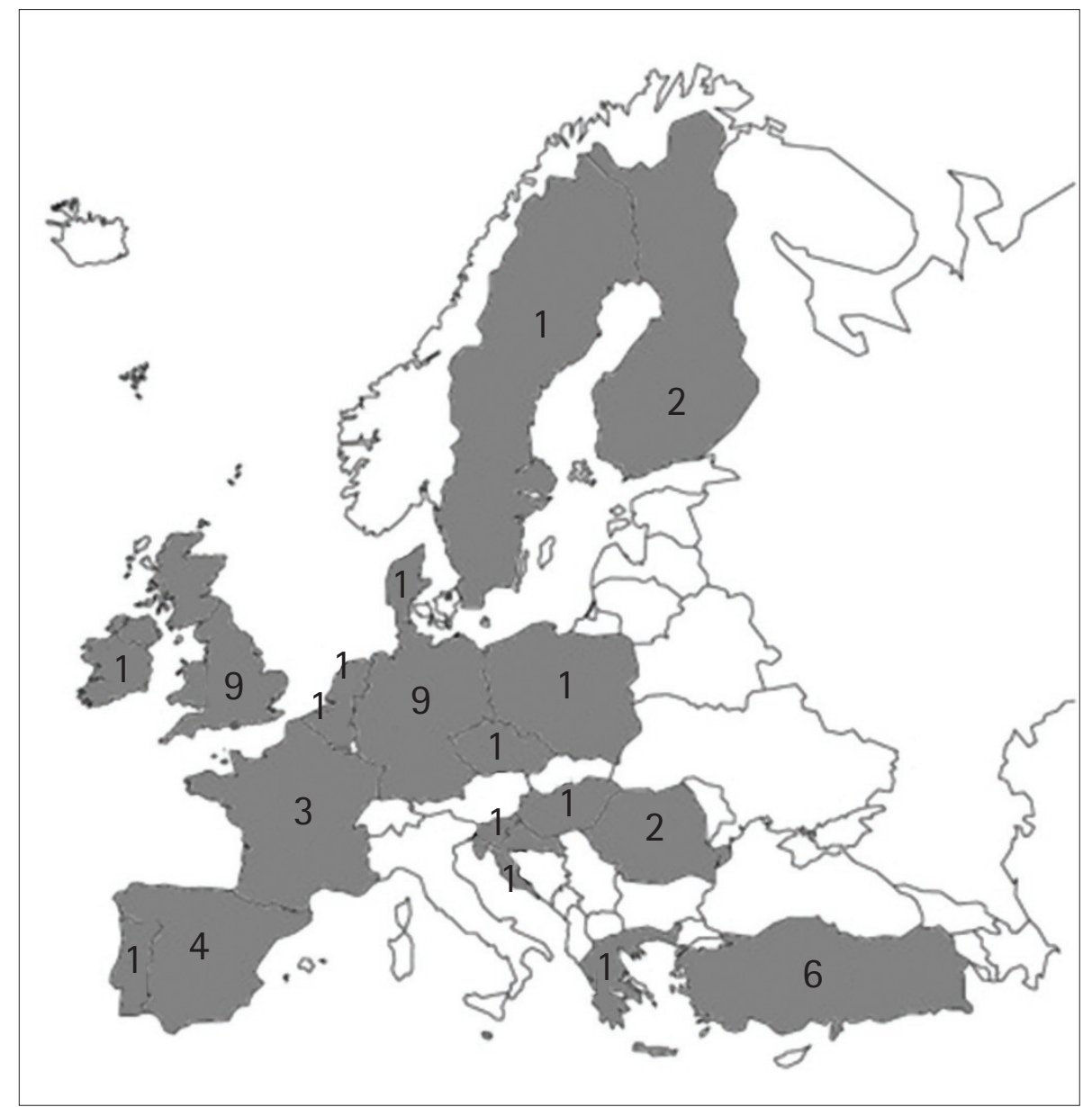

Fig. 1 Questionnaire responses per country

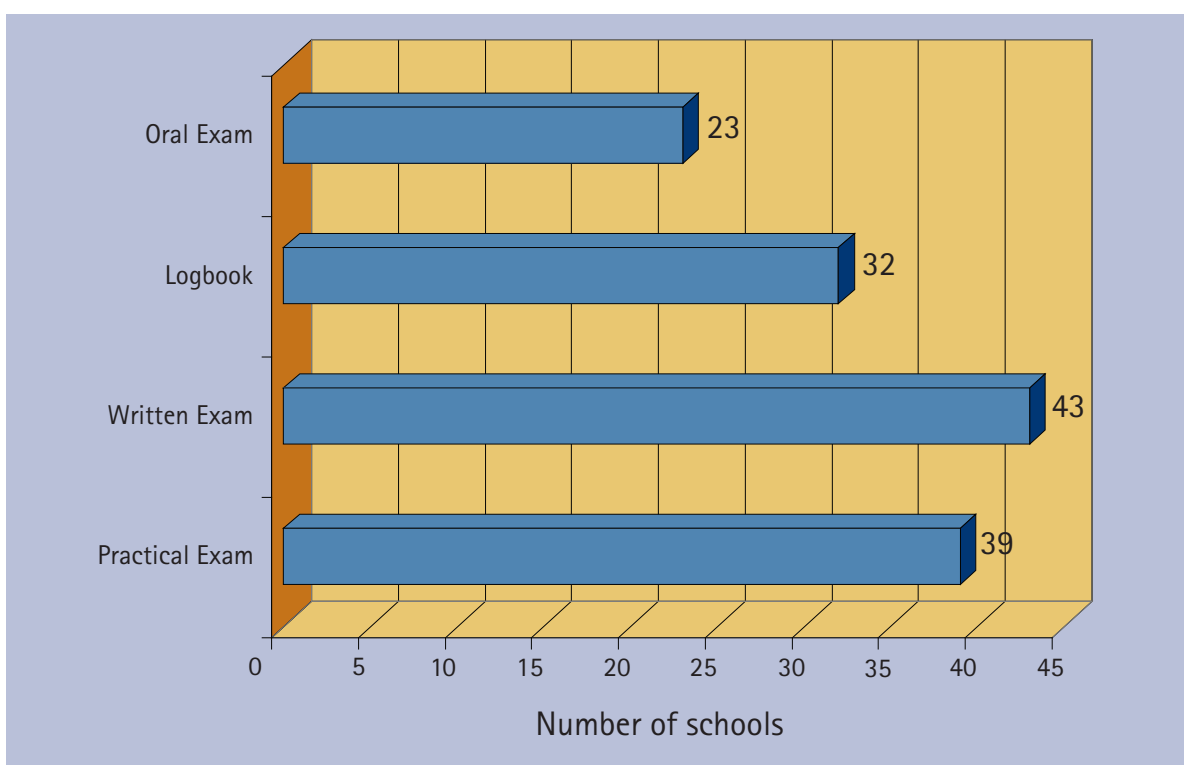

Fig. 2 Assessment methods used for RCT

which provide further details on what they suggest ought to be incorporated into the curriculum. ${ }^{22}$

\section{RATIONALE}

Previous studies have indicated a great range in undergraduate requirements, teaching and assessment with regard to root canal treatment. ${ }^{19,20}$ Since the publication of the European guidelines and the Profile and Competences Document, little research has been conducted in this area. The present study aims to assess whether there is currently convergence of requirements with regard to root canal treatment for undergraduates in the European Union. 


\begin{tabular}{|l|l|}
\hline \multicolumn{2}{|c|}{$\begin{array}{l}\text { Table } 1 \text { Schools grouped by minimum } \\
\text { number of canals required prior to graduation }\end{array}$} \\
\hline $\begin{array}{l}\text { Minimum number } \\
\text { of canals }\end{array}$ & $\begin{array}{l}\text { Percentage of } \\
\text { schools }\end{array}$ \\
\hline $1-10$ & 49 \\
\hline $11-20$ & 33 \\
\hline $21+$ & 18 \\
\hline
\end{tabular}

\section{MATERIALS AND METHODS}

A confidential online survey was created, using Bristol Online Survey software, developed by the Institute for Learning and Research Technology. This software collates data electronically for analysis. The survey was brief, with eight questions in total, including two questions covering demographics. Where possible, anticipated responses were provided as multiple-choice questions and, when appropriate, more than one option could be checked. Each question also provided space for free text entry for further explanation of responses if required.

Ethical approval was gained from the Cardiff University Dental School Ethics Committee. It was made clear to participants that the information provided would be treated confidentially and used to form this report. A list of email addresses was compiled, using addresses from the Directory of European Dental Schools of the Association for Dental Education in Europe, links with Erasmus students' schools and addresses provided by individual school websites found through information in the EU Manual of Dental Practice. ${ }^{23,24}$ The list contained email addresses for 192 out of the 198 dental schools in the EU, and the three EU candidate countries (Croatia, the former Yugoslav Republic of Macedonia and Turkey). Each school was sent a link to the online survey and asked if they would complete it.

After the initial email, second and third mailings were made to any non-responding schools at intervals of three weeks.

\section{RESULTS}

Forty-eight dental schools, spread across 20 countries, provided responses to the questionnaire. Twenty-five schools answered every question - twenty-three did not answer the final question regarding a description of competence in root canal treatment. Replies came from Belgium,

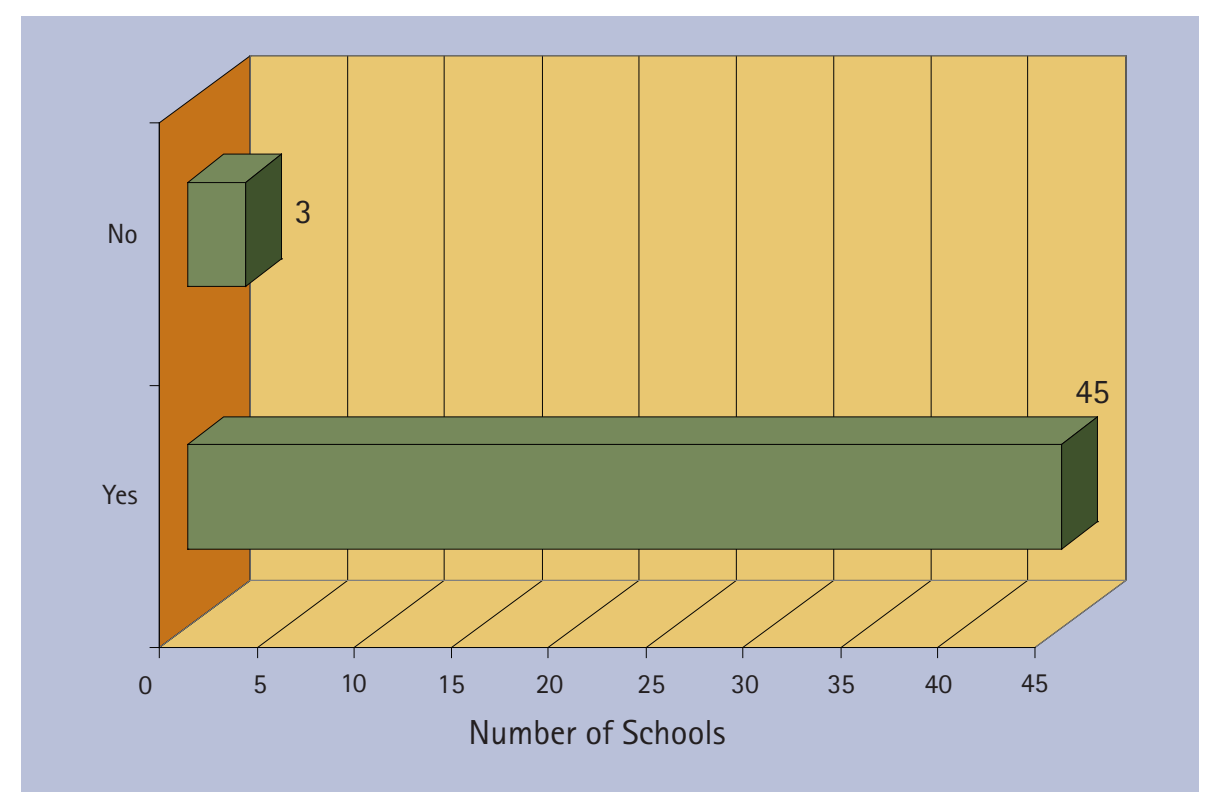

Fig. 3 Number of schools requiring anterior and posterior RCT

Croatia, Czech Republic, Denmark, Finland, France, Germany, Greece, Hungary, Ireland, Malta, The Netherlands, Poland, Portugal, Romania, Slovenia, Spain, Sweden, Turkey and the United Kingdom. The greatest number of responses from one country was nine, which came from both Germany and the United Kingdom (Fig. 1).

\section{Assessment methods}

If you assess learning in root canal treatment at undergraduate level, which method(s) do you use?

All schools stated that they assess learning in undergraduate root canal treatment. The most common assessment method was the written examination, with $90 \%$ of schools choosing this format (Fig. 2). Slightly fewer schools (81\%) use practical examinations. Logbooks or portfolios of clinical experience in root canal treatment are required in $67 \%$ of schools and $48 \%$ use oral examinations. Three schools require students to complete case reports of any root canal treatment. One school stated that students 'perform evaluations' of both their clinical and pre-clinical root canal treatments.

\section{Requirements}

Do undergraduates in your dental school have to perform a minimum number of root canal treatments before graduation?

Eighty-one percent of schools state a minimum number of root canal treatments which undergraduates must perform before graduation. This minimum number ranges from three to 80 canals with an average of 17 canals. Eight schools also ensure students perform a certain number of pre-clinical root canal treatments before commencing clinical experience. Table 1 shows the responses grouped by minimum number of canals with the most common group being 1-10 canals.

Do undergraduates in your dental school have to perform root canal treatment in both posterior and anterior teeth before graduation?

Ninety-four percent of schools require students to perform root canal treatment in both posterior and anterior teeth (Fig. 3). Several schools prefer students not to treat multi-rooted teeth until later years of the undergraduate course.

\section{Is it a requirement that undergraduates in your dental school perform root canal retreatment?}

Root canal retreatment is a requirement of undergraduates in $79 \%$ of schools in this sample. Several of the schools in which retreatment is not compulsory acknowledged that while it is not a requirement, it is almost inevitable due to insufficient primary cases.

\section{Is it a requirement that} undergraduates in your dental school perform endodontic surgery?

Four percent of schools stated that it is a requirement for their undergraduates to perform endodontic surgery. 


\section{Descriptions of competence in root canal treatment}

\section{How would you describe 'competence} in root canal treatment'?

There were 25 responses to this open-format question. Forty-four percent of respondents emphasised the role of knowledge and experience of different techniques as contributing to competence in root canal treatment. One school actually highlighted elements of technique they consider important; 'anaesthesia, rubber dam and length control'. Forty percent included diagnosis of pulpal disease in the definition of competence asserting that students should be "capable of diagnosing and treating diseases affecting the pulp and periapical tissues' and the diagnosis should be based on 'clinical and radiographic findings'. Thirty-two percent felt that the outcome and method of competent root canal treatment should meet 'acceptable standards'. Twenty-eight percent suggested that competence implies ability to undertake 'uncomplicated' or 'simple' root canal treatment and $8 \%$ highlighted that this should be performed unsupervised. In addition, three schools referred to the ESE guidelines stating that students should be able to:

'Perform root canal treatments according to recommendations of the ESE.'

'Prepare and obturate canals in accordance with the recognized ESE guidelines.'

'Complete root canal treatment in accordance with the quality guidelines of the ESE.'

Some descriptions of competence were vague, eg 'To treat a patient's tooth in acceptable quality and time.'

'When you know how to and can do a good treatment.'

Two UK schools appeared sceptical about competence at undergraduate level, eg:

'We can only work with the definition encapsulated within the GDC's The first five years. Sadly this is unachievable and I'm not sure we secure competence within that definition for most graduates.'

'The GDC definition is our goal, but we recognize that it is not achievable within the undergraduate curriculum.'

\section{DISCUSSION}

This survey was conducted using the internet because information had to be gathered from a large area in a relatively short space of time. Online surveys facilitate data collection from a broad geographical area since they allow an immediate response and real-time analysis.

One limitation of this study is that the survey was only provided in English. There was also a problem identifying up-to-date contact details for appropriate people within dental schools. Although databases exist (eg ADEE database), many of the addresses they contain are not current nor are the lists comprehensive. Several school websites also lacked the latest contact details for staff. This could, in part, be due to the frequency of staff changes in higher education institutions. It should also be borne in mind that academic staff probably receive many requests for similar information and there is little incentive for them to complete such surveys. However, as Figure 1 shows, the range of countries which responded to the present survey was ample for an overview of the current status of undergraduate root canal treatment in the EU and it represents the potential foundation of a network of contacts.

The prevalence of untreated apical periodontitis among EU countries has been shown to be high, indicating a need for graduates able to address this current health issue. ${ }^{1-4}$ Although endodontics is now a recognised specialty in several EU countries, a large proportion of root canal treatment is still performed by general dental practitioners. Studies in the UK, France and Spain have revealed that many practitioners perform root canal treatment which is not in line with current guidelines and that the standard achieved is generally not high..$^{5-9}$

At present a competency-based education is provided in many institutions with a view to achieving improved standards in clinical practice. Competency-based education allegedly encourages students to critically assess their work, a skill which is crucial in improving standards in healthcare. The major problem for endodontics is breaking down root canal treatment into objective, measurable elements. It is the hope of the European Society of Endodontology that newly qualified EU graduates will have the minimum level of competence as described within their guidelines. ${ }^{22}$

Competence in the context of dental education has been described in a variety of ways but most consider knowledge, skills and values as fundamental. Put succinctly, "competency means the behaviour expected of beginning independent practitioners. ${ }^{25}$ Competence is considered to be a mid-stage in the continuum from beginner to master in a discipline and not the end-point. Chambers ${ }^{25}$ suggests that a competent student is able to make choices between effective procedures, knows and understands the applications involved, can respond appropriately to a 'reasonable range of variation' and can recognise their limitations. At this stage students are independent practitioners and apply standards gained from teaching and experience to use their knowledge and skills. ${ }^{25}$

In the present survey, the respondents were asked to define competence in root canal treatment. Considering the emphasis in many modern dental curricula to achieve competence in specified areas, it was surprising to find such disparity between the definitions provided by those very people charged with assessing undergraduates. Many focused on the skills involved in successful treatment but failed to emphasise that those skills need to be put into the broader context of understanding the rationale for treatment and the ability to perform independently. Only $12 \%$ of schools acknowledged the role of the European Society of Endodontology curriculum and quality guidelines ${ }^{22,26}$ in describing or measuring competence. If it is the aim of dental schools to produce graduates competent in root canal treatment then they ought to be able to define the qualities that make a student competent. Without an adequate definition to work towards, what are schools looking for in their assessment of students?

It was not the aim of this study to debate the meaning or suitability of the concept of 'competence' in dental education. However, we did set out to discover if dental educators held a shared understanding of the term. This section was not completed well, perhaps as a result of the confusion over the term, or the fact that it is not a universal concept in dental education. The results indicate that there is a variation in the understandings of the term 'competence'. In this context the findings agree with those of Licari and Chambers ${ }^{27}$ although these authors saw the 'openness of the competency concept' as something of value. Our concern lies in this concept 
being used as a form of common currency within the EU as a predictive indicator of future (clinical) performance. We would argue that even assuming a basic level of technical ability, the desire to perform at an acceptable level is as much a matter of professionalism (desire to do one's best and to consider if one's best is good enough) as it is of competence.

Appropriate assessment regimes reinforce the acquirement of both skill and knowledge and are integral to a competency-based curriculum. They ensure undergraduates achieve agreed competencies by graduation. The European guidelines state 'demonstration of competence should involve both formative and summative assessment. ${ }^{22}$ It has been suggested that effective formative methods of assessing competence are the Objective Structured Clinical Examination (OSCE) and the Structured Clinical Operative Test (SCOT). ${ }^{22}$ The OSCE has been found useful for assessing diagnostic, interpretative and treatment planning skills, while the SCOT assesses individual elements of clinical skills on real patients under supervision. ${ }^{28,29}$ While several schools mentioned use of an OSCE system, no schools highlighted the use of a SCOT.

Summative assessment should take the form of written or oral examinations or presentation of completed treatments. ${ }^{22}$ One school stated students may get:

'written and oral questions as part of restorative exams,' and another explained:

'endodontic questions are included in the final written examination in Dental Pathology, Operative Dentistry and Endodontics.'

The European guidelines emphasise that 'consideration should be given to providing examinations specifically in endodontics. ${ }^{22}$ However, few schools stated that they provide an examination exclusively in endodontics. Ninety percent of the sample schools appear to provide both formative and summative assessment in root canal treatment and therefore fulfil current guidelines.

The European guidelines express that the graduating student must 'demonstrate satisfactory non-surgical root canal treatment of single rooted and multirooted teeth' and the majority of dental school requirements
(94\%) were in accordance with this. ${ }^{22}$ Interestingly, most schools (79\%) also required students to perform root canal retreatment, which is not necessarily what the European guidelines mean by 'experience of non-surgical root canal retreatment of single and multirooted teeth.'22 The European Society of Endodontology does not consider it appropriate for undergraduates to perform surgical root canal treatment. It is therefore surprising that a minority of schools (4\%) still hold endodontic surgery as a requirement.

The EU dental schools which do not comply with the European guidelines may not be producing graduates with the skills or experience in root canal treatment which are usually expected of a general dental practitioner in the EU. While it is recognised that across the EU, there are differences in allocation of resources to teaching, the results of this study suggest that there are some schools which should review their requirements for root canal treatment, since current guidelines are considered minimum requirements. ${ }^{24,30}$

Competency-based education focuses on quality rather than quantity of treatment. However, $81 \%$ of schools in this sample still required a minimum number of root canal treatments to be performed by undergraduates. It is clear from the results of this survey that numerical requirements enforced are wide-ranging and there is little consistency even within a single country. The results from Germany for example provided a range of requirements from 1 to 12 canals minimum and in the UK the range was from no minimum up to 20 canals. This suggests that the great variation in requirements cannot simply be explained by factors local to each country, such as oral conditions of the population or physical resources. Lee et $a l .{ }^{31}$ recommended that the amount of clinical experience in root canal treatment obtained by students should be determined by 'evidence of competence and not by subjective estimates of what is appropriate.' Nevertheless, the European guidelines assert 'a minimum number to gain the requisite experience is probably necessary. ${ }^{22}$ They set this minimum number at 20 teeth including extracted teeth. Since those 20 teeth should include experience of both single and multirooted teeth, then in terms of canals the figure should be greater than 20 . In this survey, only $18 \%$ of schools require undergraduates to perform root canal treatment on more than 20 canals (Table 1). Almost half of the dental schools set their requirement at ten canals or fewer. This suggests that the majority of EU graduates are qualifying with considerably less experience in root canal treatment than currently recommended by the European specialist body. In 1989, Brookman noted that a majority of new dental graduates expressed 'dissatisfaction with the content of endodontic teaching' received as an undergraduate. ${ }^{32}$ With this in mind it is hardly surprising that more recent surveys of new UK graduates have shown a large proportion of students felt they required greater training and practical experience in root canal treatment as an undergraduate. ${ }^{33,34}$

In a study by Stewardson et al. ${ }^{35}$ it was established that confidence levels of graduates correlate with the number of cases completed as an undergraduate. Gaining confidence to use the acquired practical skills and knowledge should be at the heart of any curriculum and it seems clear that assessing practical competence alone does not guarantee a graduate who is comfortable using their skills. It is also evident that while competence may be achieved by some students before reaching the minimum requirement suggested by European guidelines, the experience and confidence gained from completing that minimum should be seen as necessary for a wellrounded education.

In 1995, the FDI World Dental Federation issued a statement about the equivalency of dental diplomas. ${ }^{36}$ Within this statement, the FDI maintained that 'in the interest of protecting and enhancing the oral health of the population and the professional values of the dental profession', they support the concept of freedom of movement of dentists on the condition that their 'training and education are equivalent. ${ }^{36}$ It was recommended that appropriate dental professional organisations evaluate this equivalency and therefore candidates' rights to practise in their country. With freedom of movement already permitted in the EU, it is implied that dental training and education have been judged equivalent. However, it is apparent from the present study that some EU graduates do not show evidence of conforming to 
the current European curriculum guidelines for endodontics and therefore their equivalence in this area may be questionable. Nevertheless, the guidelines of the European Society of Endodontology have no official status; rather it is the licensing body of each country which dictates policy.

\section{Future research}

In future research it would be beneficial to establish why some schools choose to deviate from the European guidelines for endodontics. The present survey does not ascertain whether this is due to lack of resources or difference of opinion regarding requirements. This would clarify whether dental schools feel the current EU guidelines are realistic and appropriate and if so what needs to be done for more graduates to reach the European Society of Endodontology targets.

\section{CONCLUSION}

Despite convergence of the undergraduate curriculum being endorsed by many ${ }^{11,12}$ and movement of dentists within the EU escalating, ${ }^{10}$ there is still inconsistency in the output of dental schools with regard to root canal treatment experience. This sample demonstrated diversity in requirements and assessment methods, and deviation from the European Society of Endodontology's Undergraduate Curriculum Guidelines. ${ }^{22}$

1. Georgopoulou M K, Spanaki-Voreadi A P, Pantazis $\mathrm{N}$, Kontakiotis E G. Frequency and distribution of root filled teeth and apical periodontitis in a Greek population Int Endod J 2005: 38: 105-111.

2. Jimenez-Pinzon A, Segura-Egea J J, Poyato-Ferrera $M$, Velasco-Ortega E, Rios-Santos J V. Prevalence of apical periodontitis and frequency of root filled teeth in an adult Spanish population. Int Endod J 2004; 37: 167-173.

3. Loftus J J, Keating A P, McCartan B E. Periapical status and quality of endodontic treatment in an adult Irish population. Int Endod J 2005; 38: 81-86.

4. De Moor R J, Hommez G M, De Boever J G, Delme K I. Martens G E. Periapical health related to the quality of root canal treatment in a Belgian population. Int Endod J 2000; 33: 113-120.

5. Dummer P M H. The quality of root canal treatment provided by general dental practitioners working within the General Dental Services of England and Wales. Dent Profile 1998; 19: 8-10.

6. Stewardson D A. Endodontic standards in general dental practice - a survey in Birmingham, Part 1. Eur J Prosthodont Restor Dent 2001; 9: 107-112.

7. Saunders W P, Saunders E M, Sadiq J, Cruickshank E. Technical standard of root canal treatment in an adult Scottish sub-population. Br Dent J 1997; 182: 382-386.

8. Boucher Y, Matossian L, Rilliard F, Machtou F. Radiographic evaluation of the prevalence and technical quality of root canal treatment in a French subpopulation. Int Endod J 2002; 35: 229-238.

9. Sequra-Eqea J J, Jiménez-Pinzón A, Poyato-Ferrera $M$, Velasco-Ortega E et al. Periapical status and quality of root fillings and coronal restorations in an adult Spanish population. Int Endod J 2004 37: 525-530

10. Information Centre for Health and Social Care. NHS Dental Activity and Workforce Report England 31 March 2006. http: //www.ic.nhs.uk/pubs/dwfactivity Accessed 13 October 2006.

11. Banoczy J. Harmonisation of dental education and curricula in Europe. Int Dent J 1999; 49: 69-72.

12. Association for Dental Education in Europe. Aims of ADEE. http://adee.dental.tcd.ie/index. php?file=general_information.html Accessed 20 October 2006

13. European Commission. ERASMUS. http: //ec.europa. eu/education/programmes/Ilp/erasmus Accessed 14 March 2007

14. The European Higher Education Area. Bologna Declaration. 19 June 1999.

15. Dental Directives, 1978. (78/686,687.688/EEC).

16. Shanley D B, Barna S, Gannon P et al. Undergraduate training in the European Union. Convergence or divergence? Eur J Dent Educ 1997; 1: 35-43.

17. Plasschaert A J M, Holbrook W P, Delap E, Martinez C. Walmsley A D. Profile and competences for the European dentist. Eur J Dent Educ 2005; 9: 98-107.

18. Dummer PM H. Comparison of undergraduate endodontic teaching programmes in the United Kingdom and in some dental schools in Europe and the United States. Int Endod J 1991: 24: 169-177.

19. Qualtrough A J, Whitworth J M, Dummer P M H Preclinical endodontology: an international comparison. Int Endod J 1999; 32: 406-414.

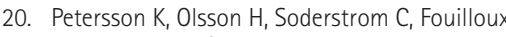
I, Jegat N, Levy G. Undergraduate education in endodontology at two European dental schools. A comparison between the Faculty of Odontology, Malmo University, Malmo, Sweden and Faculty of Odontology, Paris 5 University (Rene Descartes), France. Eur J Dent Educ 2002; 6: 176-181.

21. General Dental Council. The first five years: a framework for undergraduate dental education. 2002.

22. European Society of Endodontology. Undergraduate Curriculum Guidelines for Endodontology. Int Endod J 2001; 34: 574-580.

23. Association for Dental Education in Europe. Directory of European dental schools, 2000 http://adee.dental.tcd.ie/members Accessed 15 October 2006.

24. Kravitz A S, Treasure E T. EU manual of dental practice. Brussels: EU Dental Liaison Committee, 2004.

25. Chambers D W, Gerrow J D. Manual for developing and formatting competency statements. J Dent Educ 1994; 58: 361-366.

26. European Society of Endodontology. Quality guidelines for endodontic treatment: consensus report of the European Society of Endodontology. Int Endod J 2006; 39: 921-930.

27. Licari FW, Chambers D W. Some paradoxes in competency-based dental education. J Dent Educ 2008; 72: 8-18.

28. Mossey P A, Newton J P, Stirrups D R. Scope of the OSCE in the assessment of clinical skills in dentistry. Br Dent J 2001; 190: 323-326.

29. Mossey P A, Newton J P. The Structured Clinical Operative Test (SCOT) in dental competency assessment. Br Dent J 2001; 190: 387-390.

30. Qualtrough A J, Dummer P M H. Undergraduate endodontic teaching in the United Kingdom: an update. Int Endod J 1997; 30: 234-239.

31. Lee C 0 , Anderson D M, Wright G L Ritchie G M, Feil P H. Student endodontic performance with and without numerical requirements. J Dent Educ 1994; 58: 768-770.

32. Brookman D J. Vocational trainees' views of their undergraduate endodontic training and their vocational training experience. Int Endod J 1989; 24: 178-186.

33. Murray F J, Blinkhorn A S, Bulman J. An assessment of the views held by recent graduates on their undergraduate course. Eur J Dent Educ 1999; 3: 3-9.

34. Patel J, Fox K, Grieveson B, Youngson C C Undergraduate training as preparation for vocational training in England: a survey of vocational dental practitioners' and their trainers' views. Br Dent J 2006; 201 (Suppl): 9-15.

35. Stewardson D A, Shortall A C C, Lumley P J. Endodontics and new graduates, Part 2: undergraduate experience and course evaluation. Eur Prosthod Rest Dent 2003; 11: 15-21.

36. FDI World Dental Federation. Statement on 'The equivalency of dental diplomas.' 1995 